\title{
Information Management in Large-scale Disaster Exercises: An Integrated Perspective
}

\author{
Kenny Meesters \\ Delft University of Technology \\ k.j.m.g.meesters@tudelft.nl
}

\author{
Yan Wang \\ Delft University of Technology \\ y.wang-16@tudelft.nl
}

\begin{abstract}
Simulation exercises are fundamental for building knowledge, skills and capacities of participants to effectively address challenges in crisis management. A key element in emergency response and exercises are the capacities to work with information to support decision-making processes. However, not only exercise participants are dealing with challenges in information management (IM), but those controlling and directing exercises as well. Dynamic environments of exercises require IM capacities -for participants and directors- to optimize training opportunities.

Despite common challenges, IM activities of exercise directors and participants have so far been considered as separate fields. This paper looks at these two perspectives as part of an integrated system and examines the similarities and differences of IM in two large-scale exercises. The parallels between them present options to further explore how alignment and -more importantly- synergy of IM practices between exercise participants and directors could improve the quality of information management training in exercises.
\end{abstract}

\section{Introduction}

In recent years, due to climate change and extreme weather events, coupled with increased urbanization and the strain on natural resources, more and more people are facing the risk of being affected directly or indirectly by disasters [1]. Moreover, these disasters and their effects, coupled with an increasing involvement of various humanitarian actors and emergency response organizations, make interventions to support these (vulnerable) communities increasingly complex [2]. As such, the decision-making process in the wake of disastrous event is a complex undertaking with the need for accurate, timely and relevant information [3]. It is clear that these developments coupled with the profusion of information and communication technologies in the field of disaster response, have led to an increased awareness, investments, and prominent role of IM during disasters $[4,5]$.

IM focuses on collecting, processing, analyzing and disseminating information during disaster response. Simulation exercises have been used as important training instruments for crisis responders and humanitarian aid workers on various operations including IM [5]. Exercises are a fundamental part of building the necessary capacity and required capabilities to effectively deal with information during and after disasters.

When considering the role of IM associated with exercises, a dual perspective (Figure 1) can be taken which is linked to the directors who organize, execute and control the exercises and the participants who practice and get trained in the planned activities in exercises. Both directors and participants interact with the exercise environment. Exercise directors design and monitor the environment by injecting information/events to the participants. The participants collect and make sense of the information from the exercise environment and communicate with other participants in order to jointly carry out the response activities.

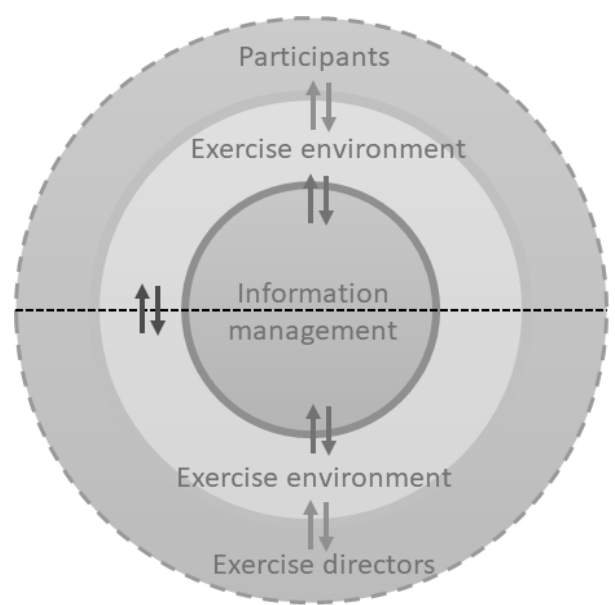

Figure 1 Dual perspective of IM in exercises 
The two perspectives mentioned above seem to be operating at different levels and independently from each other. The information use and IM responsibility within the exercise lies primarily with the exercise participants. They are challenged with various tasks such as coordination challenges and analytical tasks which require proper management of information to be effectively completed. On the other hand, the IM of the exercise management lies primarily with the exercise directors. They require information to monitor and assess the exercise progress. One could argue that the IM tasks for exercise participants are more challenging since the situational information in the exercise scenario are less known by them in advance. Nevertheless, the exercise environment also presents demanding tasks on IM for the directors, as the execution of the designed scenario is an interactive process in a multiactor environment.

In this paper the similarities and differences in IM of large-scale exercises for directors and participants are examined. Moreover, it explores how IM from one perspective influences the other one, and the relationship between their interaction and quality of information generated in exercise environment. The outcome will enable a rich, engaging learning and training environment for IM during crisis situations.

\section{Background}

Exercises and capacity building have long been a fundamental cornerstone of building up the required capacities, knowledge and skills to effectively deal with disasters and unexpected emergencies. In the past decades, IM has been established as its own discipline and field in both crisis response and training.

\subsection{Capacity Building}

IM, much like many other aspects in the field emergency response and disaster management, requires the build-up of sufficient capabilities and capacities for effective deployment during emergencies. Different national government services and international organizations offer specialized courses in the field of IM. The United Nations Office for the Coordination of Humanitarian Affairs (UN OCHA) offers for example the Coordinated Assessment and Information Management course (CAIM), the European Union Directorate General for Humanitarian Aid and Civil Protection (DG ECHO) offers various trainings as part of their Union Civil Protection Mechanism (UCPM) in which IM is prominently featured. Furthermore, a myriad of IM courses exists within academic, private and public institutes.
However in a study by the national learning center it is demonstrated that classroom exercises have little retention potential [6]. As shown in Figure 2 , only about 5 percent of what people hear in a classroom is retained. Other passive methods score higher on the pyramid, although retention percentages remain relatively low. To achieve a higher retention rate participatory method should be used. For example by doing a practical exercise around $75 \%$ of the information is retained, when students are able teach and reflect upon other the retention rate is even shown to go up to $90 \%[7,8]$. While there is debate about the specific numbers, these and other studies agree that -in addition to providing knowledge- other, engaging methods for improving the retention rate should be employed.

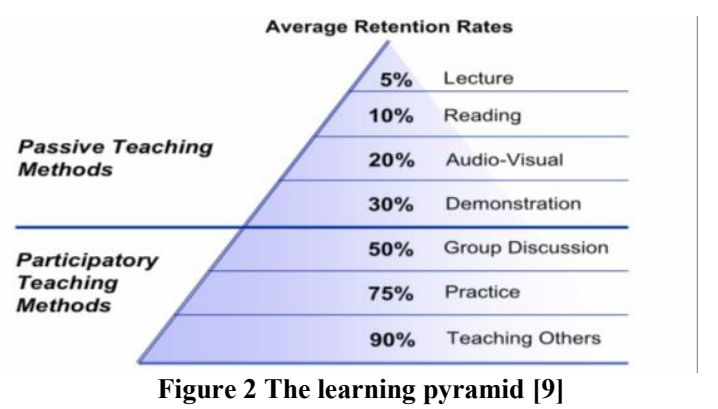

\subsection{Disaster Exercises}

While trainings enable participants to acquire the necessary skills and knowledge in the field of IM, the application of this gained capacity during emergencies requires often a more comprehensive environment $[5,10,11]$. In other words, although IM-specific training offers a valuable training opportunity, applying this knowledge in a realistic environment is necessary to ensure that these skills can be used in emergencies and while under stress.

Simulation exercises come in various forms (Figure 3), ranging from full-scale field exercises to table-top games and more conceptual analytical models. Even though full-scale exercises require more resources and efforts to set up and conduct in comparison to 'light-weight' exercises, it can provide a more immersive experience for participants. The post-disaster environment set up in this type of exercises approximates comprehensive field conditions [12] as close to a realistic intervention as possible [13]. Such realistic environment allows trainings to provide valuable results [14]. Field exercises comprise a series of events and a group of stakeholders. The creation of exercise environment requires tremendous amount of interactions among people and materials alongside those events triggered by an exercise scenario. 


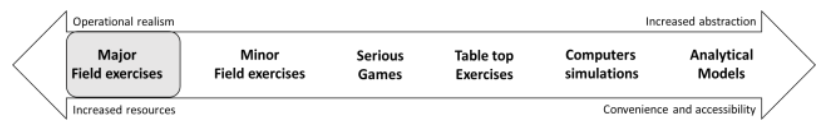

Figure 3 Types of exercises (adapted from [15])

\subsection{Exercise management and IM activities}

Medium to large simulation exercise achieves a high level of operational realism [16] meanwhile is extremely complex to design and manage at the same time. Such exercise is often organized with numerous national or international organizations, have multiple objectives and run parallel activities across various locations. Exercise management typically covers three phases, namely the pre-event phase, the event phase and the post-event phase [15], and involves three perspectives (organization, players and environment) in the exercise planning, delivery and execution (Figure 4) [17].

The IM of exercises creates environment which facilitates consistent understanding of exercise tasks and timely updates among all the exercise participants. For instance, Meesters, Van Beek and Van De Walle [18] created two connected exercise environment, i.e. the social media (online) environment and the in-field environment, and scenarios to engage exercise participants and responders across the 2 environment. The IM tasks included injecting important information on the social media to steer the exercise moving forward and monitoring the participants' interactions in both environments.

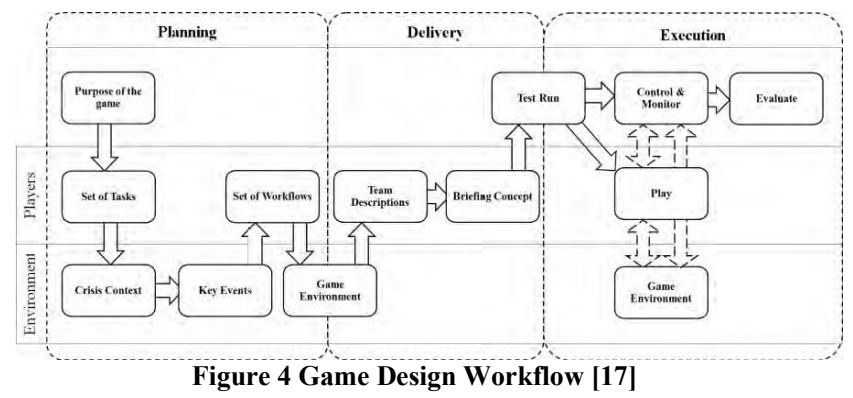

\subsection{IM and IQ in crisis management}

IM in the context of crisis management describes a complex socio-technical process that has the purpose to provide relevant information, to the right person, at the right time, in a usable form, and to enable a better understanding of the emergency and ultimately to achieve informed decision-making in the response [19]. Crisis management and humanitarian operations often encounter challenges resulted from the dynamic operating environment the communication complexities among all stakeholders and the criticality of first-time-right operations [20]. In order to minimize the impact of these challenges, it demands seamless coordination supported by proper IM practices. I.e. the improved speed and accuracy of information generated support the decision making process in these situations [21].

The general process adopted by UN OCHA [22] consists of four elements, namely collection, processing, analyzing and dissemination. During meetings, data collection efforts are organized, key notes on situational awareness are shared and activities harmonized. Experts on humanitarian affairs or policy specialists are involved in analyzing the data collected and interpret them into meaningful information. The resulting products and services are disseminated to a wide range of audience to support the development of mission strategies and operations. The importance of having a proper IM workflow has been increasingly recognized as information plays an important role in crisis situations when its added value is timely perceived. Information quality (IQ) is one of the essential drivers to realize this impact [23].

While the interpretation of IQ vary and depend on the context, the following measurements are identified in the domain of disaster management [24]: correctness, timeliness, completeness, quantity of information, context awareness and validation of information. Despite the importance an understanding of how exercises could potentially contribute to improving the IQ and IM practices in crisis management is still lacking. This is in part due to the difficulty of measuring these IQ requirements, according to various information architects from different agencies. Nevertheless a better understanding of the influential factors to IQ and IM practices and how exercises incorporate them into the exercise design and management would enable a more optimal and tailored exercise design for IM capacity building.

\section{Methodology}

This paper looks into the key elements of IM from literatures in the field of crisis management and creates a framework for assessing IM activities of exercises directors and participants. The framework is validated by being applied in two large-scale disaster exercises as case-studies (Yin, 2017). The cases presented below were chosen on the basis of the exercise type, access of the researchers, the scale of participating organizations and facilitation. While field-research during real emergencies provide valuable insights and important validation for research design, observations during real-world interventions and disaster responses are challenging [25]. Exercises therefore also provide a valuable opportunity for researchers to come to better understanding of various aspects of disaster manage. 


\subsection{Framework design}

In order to examine the IM of exercise directors and participants, it is important to understand the scope and activities of IM from these two perspectives. Based on the workflow designed in Figure 4, a set of IM activities is identified for each exercise management stage (planning, delivery and evaluation) and presented in Table 1.

Table 1 Example IM activities of and in exercises

Exercise directors Exercise Participants

Define exercise objectives, Attain situational awareness, identify/communicate with define team objectives,

0 stakeholders and their tasks, formulate exercise management workflows, design scenarios and exercise's information environment

Maintain the exercise's

information environment,

coordinate with exercise

staff, deliver information

(injects) to the participants in the exercise, ensure scenario consistency

Monitor exercise progress,

evaluate exercise

effectiveness against

exercise objectives, verify

the learning outcomes of

the exercise

While exercise directors and exercise participants have a different perspective on the exercise, they have shared objective: providing an environment that enables an optimal opportunity for building improving IM capacities. Table 1 illustrates that for each stage of an exercise design various IM activities happen for both exercise directors as well as exercise participants. However, these IM activities do not exist in isolation but influence and -even moredependent on each other. For example, the ability of participants to attain a sufficient situational awareness to deal with the crisis response, not only depends on their ability to implement an effective IM process, but also on the information (potentially) available to them in the exercise environment. Vice versa, exercise directors depend on the information attained from the exercise to determine specific actions to manipulate the exercise environment such as releasing more or less information into the exercise; as participants make certain decisions exercise directors need to update their situation.

Throughout an exercise the two IM cycles interact with each other through the various information exchange mechanisms in the exercise (such as digital platforms, role-players or other injects). As the exercise progresses both participants and directors are trying to maintain an overview of the situation and implement decisions to reach their objectives. Subsequently, the quality of the information exchanged in this shared environment is based on these decisions and derived from their situational understanding. This in turn drives the quality of the information and the information exchange between the exercise directors and the participants in the exercise environment as illustrated in Figure 5.As exercises grow larger and multiple actors enter the exercise maintaining this information cycle, the task of providing necessary information quality and an optimal training environment becomes increasingly complex for all involved.

\subsection{Case selection \& Data collection}

In order to examine the role of IM and IQ involving a large group of different stakeholders and interactions in a realistic, operational environment the authors considered various large-scale exercises in the field of humanitarian aid and emergency response. As mentioned, large-scale exercises are resource incentive and take year(s) to prepare but often occur on a cycle which enables us to anticipate various large-scale exercises. In addition to the availability of such exercises, the possibility to observe and participate in various parts of the

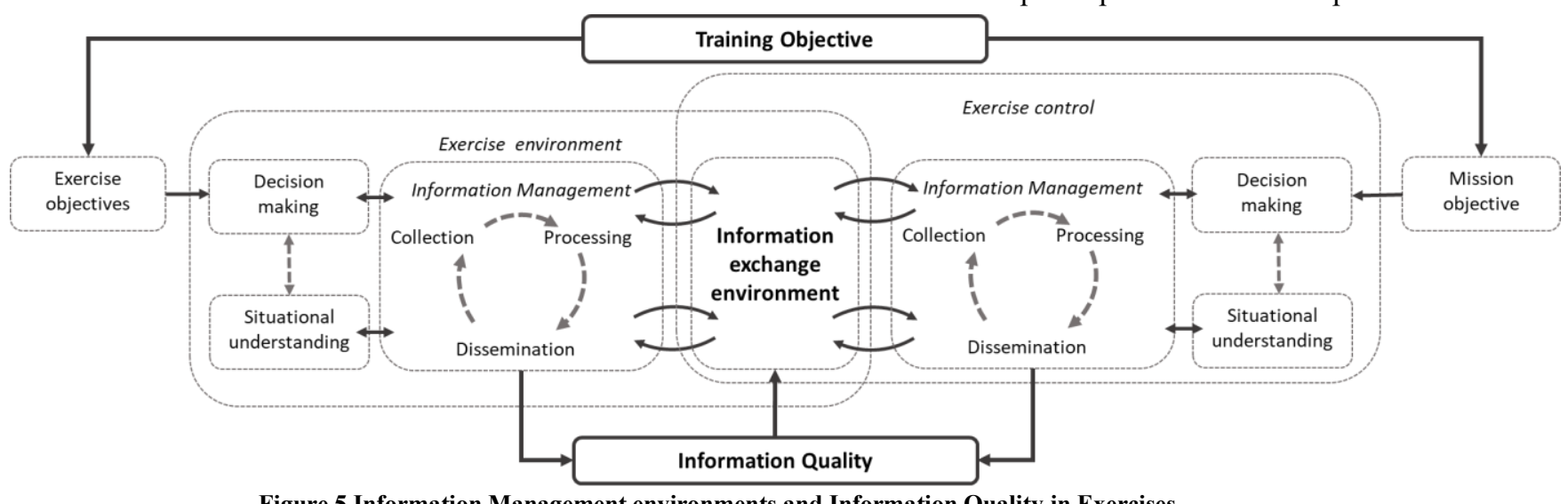

Figure 5 Information Management environments and Information Quality in Exercises 
exercise (such as evaluator, participant, role-player or exercise directors) played an important part in the selection process. Based on these criteria, two largescale disaster exercises, TRIPLEX2016 and SimEx2018, were used in this research. During both exercises the authors were involved in various aspects of the exercises such as the planning, delivery and evaluation of the exercises.

In these roles the authors were able to attain a comprehensive understanding of the IM cycles of both the exercise participants as well as the directors. During SimEx 2018 for example, one of the authors was embedded with the exercise directors, while the other author joined the exercise as IM officer. During TriplEX 2016, one author joined the central evaluation team, while the other author joined the role-players group (as both manager and role player). In both cases, the authors were embedded in the exercise directors team as well as the participants / role players to conduct participant observation [26]. By performing exercise tasks together with other participants, the authors took notes and pictures of their experiences and studied various documentation of the exercise and IM guidelines. These various roles combined provided not only a perspective on the IM activities for both exercise directors and participants, but also enable to examine the relationships between these groups in relation to the (quality of) information shared.

\subsection{Analysis}

The activities identified in Table 1 set the scope of the research and are used to collect data from the chosen cases. The various notes, pictures and other observations collected from the two exercises were first divided into two main categories: IM of exercise directors and IM of exercises participants. Next, the observed IM activities were divided into the different stages per exercises such as planning, delivery and evaluation. This was further supplemented by other documents such as exercise manuals or standard operating procedures (SOPs) from the participating organizations, resulting in an overview of the various IM activities in the exercises. The relationship between these activities and the either supplied or requiredinformation and IQ was examined, following the framework depicted in fig 5 and the information quality characteristics introduced in section 2.4 .

\section{Case study: TriplEx 2016}

TriplEx is a large-scale field simulation exercise providing a unique value as one of only few civilianrun multilateral humanitarian response field emergency simulations. The exercise regularly involves, international organizations such as the United Nations agencies and organizations or the European Union, NGOs, and military organizations'. TriplEx 2016 was managed by an international consortium managed by the Norwegian Civil Defense (DSB) and was conducted in September 2016 in southern Norway. with more than 200 participants from over 30 organizations working in the humanitarian and emergency response field.

\section{IM Activities of Exercise Participants}

As TriplEx 2016 covers a wide range of actors that jointly respond to a disaster, the IM processes are prominently featured as part of the exercise. Real and role-played organizations continuously exchange information to come to a situational understand to drive their decision-making process. Throughout the exercise various pieces of information are released to or uncovered by the participants and integrated in their IM processes.

From a participant point of view, the key IM challenges in TriplEx stems from interacting with the large number of participants. A key element in the IM cycle is to map, engage and exchange with different stakeholders including other participants and role-played organizations. To facilitate this process various real-world tools have been employed such as the Virtual OSOCC (discussion/ information platform), and Humanitarian.id (a digital identity provider / contact list). Other means for exchanging information included modalities such as meetings, briefings, and emails. Interestingly, WhatsApp played a significant role in the information exchange during the exercise among the participants.

In addition to the stakeholder engagement,

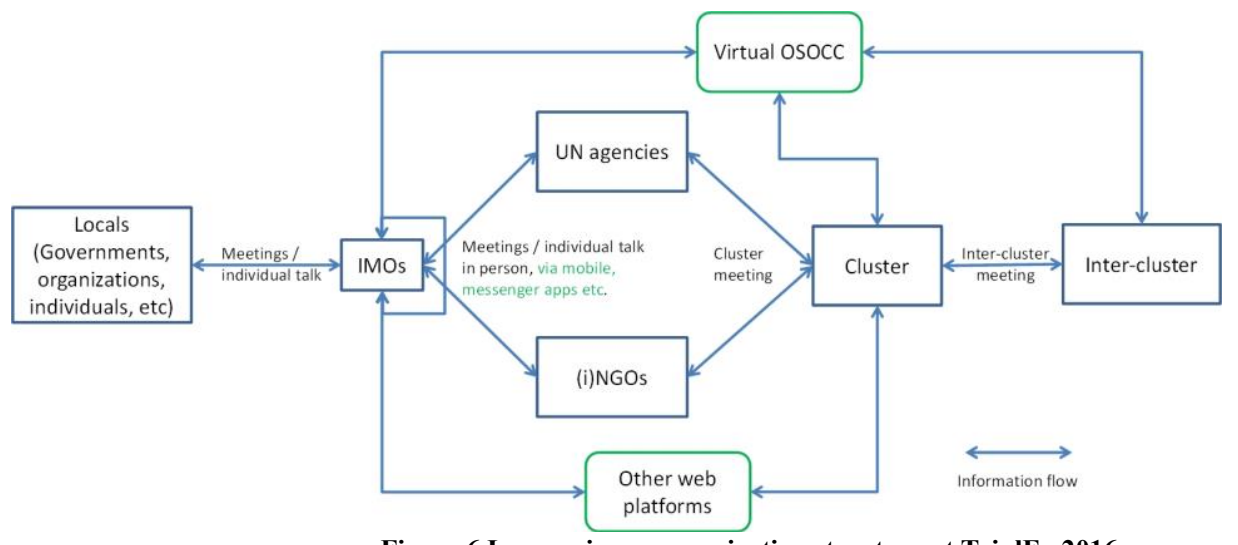

Figure 6 In-exercise communication structure at TriplEx 2016 
various other IM tasks included the collection of assessments data, either physically through engaging with role-played affected community members, or reviews of secondary data. These were again supported by various tools such KOBO (form/data collection application) and HDX (Humanitarian Data Exchange, a platform for exchanging datasets). The diagram in Figure 6. depicts the various information flows in the exercise from the participants viewpoint.

\section{IM Activities of Exercise Control}

One of the key challenges for the exercise directors was the tracking, allocation and deployment of resources such as locations, role-players and other exercise elements throughout the exercise. The size of TriplEx 2016 (both in number and geographical spread) made these challenges even harder. For example, around 65 students in related studies from three European universities to play civilian roles in various injects, in order to provide a realistic, interactive disaster environment. However, these students each had to be instructed, briefed, transported, retrieved and debriefed in multiple rotations per day. As these students provided a large portion of the information (injects) that the participants had to work with, their briefing (what information was to be exchanged) and debriefing (what was actually exchanged) was crucial for a consistent exercise environment. Similar considerations applied to other forms of information provided such as digital injects (phone, email, platform messages).

In addition, the exercise directors relied on various 'local-controllers' to be the eyes and ears in the field and report back to exercise staff where decisions could be made to adjust the exercise much like an assessment process. Finally, a separate group of evaluators was assigned to be responsible for collecting data and evaluating both the performance within the exercise and the exercise itself. The main communication between the various groups in exercise control occurred via Slack with separate channels for various parts of the exercise.

\subsection{Case study: SimEx 2018}

SimEx is an annual large-scale simulation exercise taking place in Portsmouth, United Kingdom. SimEx is comprised of two connected exercises-parts. First, the national side of the exercise focusses on the local, regional and national emergency response organizations. This includes local hospitals, regional emergency and fire-fighting services as well as national capacities and governments services. Second, the international side of the exercise focusses on the role of international agencies and (i)NGOs such as the United Nations Disaster Assessment and Coordination (UNDAC), MapAction and the Department for International Development (DIFD) of the UK government. In total the exercise involved over 40 key organizations and over 500 participants. The exercise includes a range of activities such as activation, mobilize, respond operationally on scene, report (internally and externally), implement short and medium-term plans, hand-over, demobilize and complete after-action reviews.

\section{IM Activities of Exercise Participants}

The dual nature of SimEx with both a national and international component provides specific information challenges to the participants, specifically related to the coordination. As each part of the exercise in essence can operate independently, the direct need for information exchange is limited. However, the overall effectiveness of the (inexercise) response and the individual organizations will improve if better coordination and information exchange is achieved. In other words, in contrast with TriplEx, the information exchange in SimEx is not per se driven by formal structure, organizational mandates or standards operating procedures but rather from a collaboration point of view. This requires participants to actively seek out other (participating and role-played) organization to acquire information that enables a more informed decision-making process.

As a result, the key IM challenges in SimEx 2018 included actively searching and monitoring information on various platforms, understanding and addressing the information needs of the own and other organizations to create synergy, and collaborate with (role-played) government agencies and affected communities. As an example, social media (Twitter) was used during SimEx 2018 by the role-played affected community members to not only deliver eyewitness accounts from the field, but also establish relationships through (digital) interactions. The inclusion of this aspect in the exercise required a more outward and pro-active approach of the responders.

To support this IM process not only were various tools being used such as HumanitarianResponse.info (web platform for information exchange and coordination) but also real-world support groups such as the Standby Task Force (a world-wide group of online volunteers that supports remote information management including the mapping of social media activity). Furthermore, other tools were used to track activities of stakeholders such as Slack and Trello. 


\section{IM Activities of Exercise Control}

In SimEx 2018, exercise control mainly emphasized the gathering of information through direct observations in the field and the interaction with various role players, both as affected communities as well as local government, NGOs and other organizations. A few websites with baseline data about the affected country have also been provided to the participants.

A particular challenge in SimEx 2018 was the use of (real-world) social media. This addition provided a realistic and comprehensive environment for the participants to obtain more information directly from the field (akin to real-world disaster). It also enables role-players to engage with the responders and participants organizations in other ways then face-toface contact on-site, providing a more engaging and immersive experience for them. However, maintain the integrity and consistency of the scenario throughout these various modalities for interaction is challenging for exercise directors, as some participants may take more leeway or add their own interpretation of the scenario.

In terms of learning opportunity and evaluation SimEx uses a fairly unique approach. As SimEx also involves students who are relatively new to disaster management and emergency response the core emphasis is not only on replicating an as realistic scenario for the exercise but balances this with an optimal learning environment. For example, in the UNDAC team experienced team-members are joined by students who work alongside them, fulfilling a mentoring role. This form of 'controlled players' provides not only exercise control with more monitoring options, but also ensure an optimal learning environment.

\section{Results}

In both large-scale exercises, IM plays a critical role although implemented differently. For example, in SimEx 2018, social media was actively included as part of the IM activities for participants, whereas TriplEx 2016 involved IM activities involving a wide range of actors. Likewise, the management of information on the exercise director level also differed. The information generated and injected in the exercise was mainly through a limited number of key role players, where in TriplEx a larger number of role-players generated more distributed information for the participants. However, despite these differences in implementation, for both the participants and directors, the need for proper IM and sufficient IQ to optimize their respective decisions making is a crucial prerequisite to optimize the training environment. Even more, the two information environments do not exist and operate in isolation but are dependent on each other in the various stages of an exercise (Figure 5).

\subsection{IM \& Exercise Design}

As mentioned, exercises are implemented in various stages, starting with the planning in which the exercise objectives are determined as well as the various activities in conjunction with the participants and their organizations. Transition from the planning into the execution the exercise is designed, implemented and 'delivered' to the participants. Much like the planning, the delivery is an ongoing process that requires continuous adoption based on the decisions of the participants as well as the roleplayers, controller and exercise directors. Through the planning and delivery, the evaluation is continously examining the performance of both the participants as well as the exercise directors against the learning / training objectives determined prior. In each of these steps IM and IQ are key elements to be considered to effectively and efficiently achieve these objectives.

\section{Planning}

In the planning stages of the exercise various key decisions are being made that directly influence role of information and IM in the exercise for both the participants and the exercise directors. A prime example is the scenario and the related information injects that will be delivered the participants to build their situational understanding, including how they will be delivered (digital, role-player, etc.). A particular consideration has to be given on the information exchange environments that will be put in place during the exercise and how these can enable bi-directional feedback from and to the participants and controllers.

\section{Delivery}

In the delivery of the exercise a key element is the exchange and feedback loop that occurs between the participants and the exercise staff (directors, roleplayers, controllers). Depending on the progress of the exercise real-time decisions have to be made to ensure that the exercise experience not only progresses and stays consistent but also optimizes the training or learning opportunities for the participants. Real-time interventions during the exercises may then be put in place to correct and optimize the exercise flow where needed through various injects. However, this decision-making process relies on key information from the exercise obtained in the information exchange with participants and exercise staff. 


\section{Evaluation}

As simulation exercises are primarily a training and testing environment for people, organizations, processes, and systems, evaluation is a core element in the exercise design. Evaluation is not an activity that occurs at the end of the exercise in which lessons learned are formulated and reports written. Rather, it is the continuous monitoring of the injected information, IM activities and the required IQ (see below) to ensure the training and learning objectives are reached. This requires active involvement in both the planning and delivery of the exercise, operating essentially as an IM process in which the situation (learning environment) is being monitored against the learning objectives and where necessary provide feedback to the decision makers (exercise directors).

\subsection{IQ \& Exercise design}

As illustrated IQ plays a critical role in the successful implementation of the IM process for both participants and exercise directors.

Table 2 IQ assessment of TRIPLEX2016 IM

\begin{tabular}{|c|c|c|}
\hline $\bar{Q}$ & $\begin{array}{l}\text { Exercise control to } \\
\text { participants }\end{array}$ & $\begin{array}{l}\text { Participants to } \\
\text { exercise control }\end{array}$ \\
\hline ن⿺辶 & $\begin{array}{l}\text { Information should be } \\
\text { consistent with(in) the } \\
\text { exercise scenario and } \\
\text { conflicts should be able to } \\
\text { be resolved within the } \\
\text { exercise context. }\end{array}$ & $\begin{array}{l}\text { Participants shared information } \\
\text { relies on the IM performance of } \\
\text { both them and the exercise } \\
\text { environment. Correct actions or } \\
\text { information are therefore } \\
\text { relative to exercise progress }\end{array}$ \\
\hline$\stackrel{\mathscr{\Xi}}{\stackrel{\Xi}{\Xi}}$ & $\begin{array}{l}\text { ion should either } \\
\text { lable (passive) or } \\
\text { (active) to the } \\
\text { its at the moment } \\
\text { lecisions and turn } \\
\text { the exercise. }\end{array}$ & $\begin{array}{l}\text { Information about the decisions } \\
\text { and actions of the participants } \\
\text { should be timely in order to } \\
\text { prepare appropriate responses } \\
\text { especially with many role- } \\
\text { players involved. }\end{array}$ \\
\hline 离 & $\begin{array}{|lr|}\text { The information provided } \\
\text { should be able to make } \\
\text { the correct or justified } \\
\text { decisions } & \text { while } \\
\text { considering } & \text { the } \\
\text { participants experiences } \\
\text { and background } \\
\end{array}$ & $\begin{array}{l}\text { Information from participants } \\
\text { can differ greatly with many } \\
\text { organizations involved, } \\
\text { integrating the observations in a } \\
\text { comprehensive overview is key } \\
\text { for informed interventions and } \\
\text { understanding their impact }\end{array}$ \\
\hline 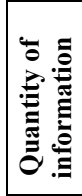 & $\begin{array}{l}\text { The amount } \\
\text { information presented in } \\
\text { the exercise should be } \\
\text { balanced with the capacity } \\
\text { and learning objective of } \\
\text { the participants }\end{array}$ & $\begin{array}{l}\text { Inform } \\
\text { particip } \\
\text { be spar } \\
\text { in la } \\
\text { requirir } \\
\text { monito }\end{array}$ \\
\hline 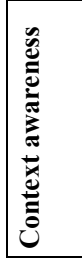 & $\begin{array}{l}\text { While improvisation can } \\
\text { be used to enhance } \\
\text { scenario, information } \\
\text { delivered in the exercise } \\
\text { should be considered in } \\
\text { relation to earlier provided } \\
\text { information or other role- } \\
\text { players }\end{array}$ & $\begin{array}{l}\text { contextual awareness } \\
\text { the exercise directors. } \\
\text { ive interventions need to } \\
\text { ler this context to ensure a } \\
\text { nging but engaging } \\
\text { nment. }\end{array}$ \\
\hline 胥 & $\begin{array}{l}\text { icipants should be able } \\
\text { alidate the information } \\
\text { ived for example by } \\
\text { igulation or reference } \\
\text { erials. }\end{array}$ & $\begin{array}{l}\text { Exercise directors need } \\
\text { able to validate inform } \\
\text { through different channels } \\
\text { as role-players and IM pro } \\
\text { provided by participants }\end{array}$ \\
\hline
\end{tabular}

In order to effectively train IM skills during an exercise both groups need to be able to attain a certain level of IQ. This has implications for planning, delivery and evaluation of an exercise. Based on the results we have identified key IQ considerations as part of this exercise design in Table 2. It is important to consider that these elements are not only key considerations in the planning or design of the exercise but -perhaps even more- during execution. However, exercise directors and roleplayers can choose to deliberately not address or deliver the required information quality as part of the training objective: e.g. conflicting information, too much, or little information. However, we consider this a deliberate design choice and part of the necessary IQ for providing an optimal training environment and the design considerations still apply.

\section{Discussion}

Simulation exercise are an important part in the emergency response and disaster management domain. Exercises allow disaster responders, humanitarian agencies and other emergency services to train, test and learn from situations that are otherwise unexpected, unknown and unfamiliar. Nevertheless, large-scale exercise has certain drawbacks. As the scale of the exercise increases and the interdependencies between the various participating organizations and individuals increase, as well as the interactions between exercise directors and participants.

\subsection{Monitoring instruments}

Both exercise directors and participants need to closely monitor the progress of the exercise and performance / well-being of participants involved. Due to advancements in information and communication technology, more and more options have become available for information managers to support various IM tasks such as the collection of data, the processing of this data into information and sharing the resulting information with others. The rapid increase in the availability and usability of these tools and services has provided new opportunities and challenges to IM.

For directors, another monitoring instrument are role players. They are part of the exercise environment and given tasks to interact with participants to steer exercises. Meanwhile they inform the directors with their in-person experience of the behavior/performance of participants. A big advantage of role playing is the flexibility of using actual people to adjust exercise scenario, yet the key is to properly (de)brief them with the objectives and necessary knowledge to fill into the context. 


\subsection{Real-time adaptation}

As large-scale exercises are usually carried out continuously throughout the days, it requires both exercise directors and participants to adapt to the evolving environment timely and continuously. While such real-time adaption is already in the nature of the IM activities of participants in real crisis situations, for exercise management it still deserves more attention. Especially considering the general training purposes of disaster exercises, it is more important to keep the exercise environment not only with a realistic scenario but, more importantly, with a focused learning environment. Therefore, being aware of the dynamic responses from participants and being able to respond to them with association to the training objectives completes the feedback loop and creates the learning cycles in exercises. This gives opportunities to properly record the behavior of participants and reflect on the actual performance of exercise participants.

\subsection{Information quality}

Exercises provide an excellent opportunity not only to practice hands-on operational and collaboration skills, but also to experiment with new technologies, strategies and tactics in a safe but realistic environment [28]. As depicted in Figure 5 the quality of information generated in the exercise is continuously influenced by both the behaviors of exercise directors and participants meanwhile influences the information environment where they interact with each other. Correct, complete, timely, sufficient, precise and reliable information injected into the exercise environment would lead to the corresponding levels of quality information captured in the exercise missions. There is a reinforcing loop between the IQ, exercise control and exercise environment which eventually determines how well the mission objectives for the exercise participants and the exercise objectives for the directors are achieved respectively.

\section{Conclusion}

Information has always been crucial in the process of informed decision and IM has become a cornerstone in effective crisis management over the past decade(s). As mentioned in the World Disasters Reports 2005, 'Information can save lives' [29]. Indeed, the value of quality information in the field of crisis management has been directly related to effective delivery of critical and lifesaving aid. IM is therefore a crucial element and a recurring element in training, capacity building and exercises for crisis responders. Nevertheless, providing a realistic, comprehensive and consistent exercise environment that enables an optimal learning environment for

This study emphasizes the importance of IM in both exercise control and crisis management. In particular, it reveals the connections between and influences of IM of exercise control and in-exercise IM. In order to achieve in-exercise IM training purposes, it is important to plan and set up proper IM environment, and constantly monitor it throughout exercises. These two levels of IM activities are strongly connected and in fact even interdependent. The information quality aspects of the IM of exercise control have direct impact on the corresponding aspects of the in-exercise IM quality. Moreover, both perspectives require the same skills, capabilities and to some extent- tools and services to effectively manage information in order to support their decision-making processes.

\subsection{Research approach}

The research presented in this paper is part of ongoing studies and represents a limited portion of the total amount of collected data throughout these (and other) exercises. The data collection, and subsequently this research, has been made possible thanks to the invitation of the various exercises' directors. At the same time the authors have actively contributed to the exercise in hands-on capacities such as role-player management, information officer or evaluator. This active participation cuts both ways: it provides additional resources and capacities to an often already resource strained- exercise but at the same time provides researchers with in-depth experiences and understanding that is otherwise hard to obtain through passive observations.

\subsection{Limitations \& Future research directions}

The results presented in this paper are based on the two large-scale exercises, both quite well known in the world of humanitarian aid and emergency response. Nevertheless, exercises, trainings and simulations come in a wide range of types which vary in multiple aspects. The findings presented above may not be representative of all simulation exercises. Therefore, more comparative work needs to be done to examine other types of exercises.

Methodologically speaking, the chosen cases reflect the core research context well, i.e. the IM in disaster exercises, despite that the number of cases is smaller than the ideal number of cases for qualitative research (four - ten cases) [30]. While fewer cases allow greater opportunities for depth of observation [31], more studies of different large-scale simulation exercises are desired as future work. 


\section{References}

[1] Ifrc, "World Disaster Report 2013", 2013,

[2] Comes, T., Meesters, K., and Torjesen, S., "Making Sense of Crises: The Implications of Information Asymmetries for Resilience and Social Justice in Disaster-Ridden Communities", Sustainable and Resilient Infrastructure, 2017, pp. 1-13.

[3] Bharosa, N., Lee, J., and Janssen, M., "Challenges and Obstacles in Sharing and Coordinating Information During Multi-Agency Disaster Response: Propositions from Field Exercises", Information Systems Frontiers, 12(1), 2010, pp. 49-65.

[4] Comfort, L.K., Ko, K., and Zagorecki, A., "Coordination in Rapidly Evolving Disaster Response Systems: The Role of Information", American Behavioral Scientist, 48(3), 2004, pp. 295-313.

[5] Crowley, J., and Chan, J., "Disaster Relief 2.0: The Future of Information Sharing in Humanitarian Emergencies", Harvard Humanitarian Initiative and UN Foundation-Vodafone Foundation-UNOCHA, 2011,

[6] Wood, E., "Problem-Based Learning: Exploiting Knowledge of How People Learn to Promote Effective Learning", 2013,

[7] Fry, H., Ketteridge, S., and Marshall, S., A Handbook for Teaching and Learning in Higher Education: Enhancing Academic Practice, 2008.

[8] Dearing, R., "Higher Education in the Learning Society", 1997,

[9] Dekanter, N., "Gaming Redefines Interactivity for Learning", TechTrends, 49(3), 2004, pp. 26-31.

[10] Carver, L., and Turoff, M., "The Human and Computer as a Team in Emergency Management Information Systems", CACM, 50(3), 2007, pp. 33-38.

[11] Comes, T., Vybornova, O., and Van De Walle, B., "Bringing Structure to the Disaster Data Typhoon: An Analysis of Decision-Makers' Information Needs in the Response to Haiyan", Book, 2015, pp. 23-25.

[12] Alexander, D., "Scenario Methodology for Teaching Principles of Emergency Management", Disaster Prevention and Management, 9(2), 2000.

[13] Meesters, K., "Towards Using Serious Games for Realistic Evaluation of Disaster Management It Tools", in (Editor, 'ed.'^'eds.'): Book Towards Using Serious Games for Realistic Evaluation of Disaster Management It Tools, 2014, pp. 38-48.

[14] Rehn, M., Andersen, J.E., Vigerust, T., Krüger, A.J., and Lossius, H.M., "A Concept for Major Incident Triage: Full-Scaled Simulation Feasibility Study", BMC emergency medicine, 10(1), 2010, pp. 17.

[15] Alexander, A.J., Bandiera, G.W., and Mazurik, L., "A Multiphase Disaster Training Exercise for Emergency Medicine Residents: Opportunity Knocks", Academic emergency medicine, 12(5), 2005.

[16] Alexander, D.E., Confronting Catastrophe: New Perspectives on Natural Disasters, Terra and Oxford University Press, 2000.

[17] Link, D., Meesters, K., Hellingrath, B., and Van De Walle, B., "Reference Task-Based Design of Crisis
Management Games", Book Reference Task-Based Design of Crisis Management Games, 2014

[18] Meesters, K., Van Beek, L., and Van De Walle, B., "\# Help. The Reality of Social Media Use in Crisis Response: Lessons from a Realistic Crisis Exercise", Book \# Help. The Reality of Social Media Use in Crisis Response: Lessons from a Realistic Crisis Exercise, IEEE, 2016, pp. 116-125.

[19] Van De Walle, B., "Review of the Operational Guidance Note on Information Management", IASC Task Force on Information Management, 2010,

[20] Wang, Y., Lukosch, H.K., and Schwarz, P., "The Role of Serious Gaming in Assisting Humanitarian Operations", International Journal of Information Systems for Crisis Response and Management, 2019

[21] Van De Walle, B., and Comes, T., "On the Nature of Information Management in Complex and Natural Disasters", Procedia Engineering, 107(2015)

[22] Ocha, "Operational Guidance on Responsibilities of Sector Cluster and Ocha in Information Management V3.0", 2014,

[23] Altay, N., and Labonte, M., "Challenges in Humanitarian Information Management and Exchange: Evidence from Haiti", Disasters, 38(s1), 2014,

[24] Bharosa, N., Appelman, J., Van Zanten, B., and Zuurmond, A., "Identifying and Confirming Information and System Quality Requirements for Multi-Agency Disaster Management", Book Identifying and Confirming Information and System Quality Requirements for Multi-Agency Disaster Management, ISCRAM, 2009

[25] Chan, J., and Comes, T., "Innovative Research Design-a Journey into the Information Typhoon", Procedia Engineering, 78(2014, pp. 52-58.

[26] Dewalt, K.M., and Dewalt, B.R., Participant Observation: A Guide for Fieldworkers, Rowman Altamira, 2011.

[27] Muhren, W.J., and Van De Walle, B., "Sensemaking and Information Management in Humanitarian Disaster Response: Observations from the Triplex Exercise", Book Sensemaking and Information Management in Humanitarian Disaster Response: Observations from the Triplex Exercise, 2009

[28] Meesters, K., and Van De Walle, B., "Serious Gaming for User Centered Innovation and Adoption of Disaster Response Information Systems", International Journal of Information Systems for Crisis Response and Management (IJISCRAM), 6(2), 2014, pp. 1-15.

[29] Cross, I.F.O.R., and Societies, R.C., "World Disaster Report 2005", Book World Disaster Report 2005, IFRC Geneva, 2006

[30] Eisenhardt, K.M., "Building Theories from Case Study Research", Academy of management review, 14(4), 1989, pp. 532-550.

[31] Voss, C., "Case Research in Operations Management": Researching Operations Management, Routledge, 2010, pp. 176-209. 